$$
\text { CONF-9606110--1 }
$$

Note: This is a preprint of a paper being submitted for publication. Contents of this paper should not be quoted nor referred to without permission of the author(s).

Invited paper for proceedings of the International Conference on Ion Implantation Technology Austin, Texas (June 17-21, 1996)

Ion Beam Synthesis of Nanocrystals and Quantum Dots in Optical Materials

C. W. White, J. D. Budai, S. P. Withrow, J. G. Zhu, and S. J. Pennycook

Oak Ridge National Laboratory

Oak Ridge, TN

R. H. Magruder

Vanderbilt University

Nashville, TN

D. O. Henderson

Fisk University

Nashville, TN

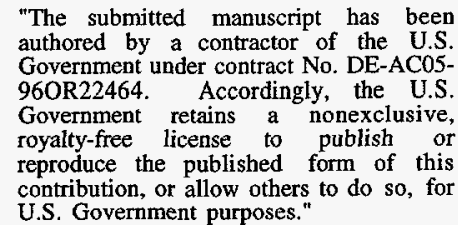

Prepared by the

Oak Ridge National Laboratory

Oak Ridge, Tennessee 37831

managed by

LOCKHEED MARTIN ENERGY RESEARCH CORP.

for the

U.S. DEPARTMENT OF ENERGY

under contract DE-AC05-96OR22464

June 1996 


\section{DISCLAIMER}

This report was prepared as an account of work sponsored by an agency of the United States Government. Neither the United States Government nor any agency thereof, nor any of their employees, makes any warranty, express or implied, or assumes any legal liability or responsibility for the accuracy, completeness, or usefulness of any information, apparatus, product, or process disclosed, or represents that its use would not infringe privately owned rights. Reference herein to any specific commercial product, process, or service by trade name, trademark, manufacturer, or otherwise does not necessarily constitute or imply its endorsement, recommendation, or favoring by the United States Government or any agency thereof. The views and opinions of authors expressed herein do not necessarily state or reflect those of the United States Government or any agency thereof. 


\section{DISCLAIMER}

Portions of this document may be illegible in electronic image products. Images are produced from the best available original document. 



\title{
Ion Beam Synthesis of Nanocrystals and Quantum Dots in Optical Materials"
}

\author{
C. W. White, J. D. Budai, S. P. Withrow, J. G. Zhu, and S. J. Pennycook \\ Oak Ridge National Laboratory \\ Oak Ridge, Tennessee 37831 \\ R. H. Magruder \\ Vanderbilt University \\ Nashville, Tennessee \\ D. O. Henderson \\ Fisk University \\ Nashville, Tennessee
}

\begin{abstract}
High-dose ion implantation has been used to synthesize a wide range of nanocrystals and quantum dots, and these structures can be encapsulated in a number of host materials using this technique.
\end{abstract}

\section{INTRODUCTION}

Nanocrystals and quantum dots have attracted considerable interest recently [1]. For sufficiently small structures, quantum confinement effects can arise when the electrons are confined to regions smaller than their delocalized length. A result of this quantum confinement is the modification of their optical, electrical, and physical properties that may lead to a series of unique optical, electrical, and magnetic devices. Many methods are being explored to synthesize nanocrystals and quantum dots. High-dose ion implantation is an ideal method to create high densities of encapsulated nanocrystals in the near surface of a wide range of host materials. Implantation produces a supersaturation of an impurity and subsequent annealing leads to precipitation and the formation of nanocrystals and quantum dots encapsulated in the host material.

This method of synthesis is applicable to the formation of a wide range of nanocrystals and quantum dots. Metallic nanocrystals such as $\mathrm{Au}$ [2-5] or $\mathrm{Cu}$ [6] have been formed in fused silica by ion implantation, and these lead to dramatic changes in the optical properties and give rise to a refractive index which depends on optical intensity. Elemental semiconductor nanocrystals $\mathrm{Si}$ and $\mathrm{Ge}$ have been formed in fused silica by ion implantation [7-12] and then can give rise to strong photoluminescence (PL) in the visible and near IR regions, although the mechanism responsible for luminescence remains under investigation [13]. Implantation can even be used to produce $\mathrm{Si}$ or Ge nanocrystals in $\alpha$ $\mathrm{Al}_{2} \mathrm{O}_{3}$, and these are three dimensionally oriented with respect to the matrix [14]. Finally, by sequentially implanting various combinations of ions to high doses followed by annealing, a wide range of compound semiconductor and alloy nanocrystals have been synthesized in a range of host materials including fused silica, $\alpha-\mathrm{Al}_{2} \mathrm{O}_{3}$, and crystalline silicon [15-22]. The ability to synthesize such a wide range of nanocrystals and quantum dots, and to control easily the stiochiometry and depth distribution of the nanoparticles makes ion implantation a very attractive method for their fabrication. Implantation may be the simplest method to produce some of these materials due to their sensitivity to high temperatures or oxidizing conditions.

To form nanocrystals by ion implantation, doses of $\sim 1 \times 10^{17} / \mathrm{cm}^{2}$ or greater are used at energies chosen to give a projected range of $-100 \mathrm{~nm}$. To form compound semiconductors or alloys, various combinations of ions are implanted at energies chosen to give an overlap of the profiles. The stoichiometry of the compound is controlled by the relative doses of the individual constituents. In our work, implanted samples are subsequently annealed in $\mathrm{Ar}+4 \% \mathrm{H}_{2}$ to induce precipitation and nanocrystal formation. Various methods have been used to characterize the nanocrystalline composites including $\mathrm{x}$-ray diffraction, transmission electron microscopy (TEM), Rutherford backscattering - ion channeling, Raman spectroscopy, and various optical measurements (absorption, PL, and infrared reflectivity).

\section{Si NANOCRYSTALS IN $\mathrm{SiO}_{2}$}

Silicon and $\mathrm{Ge}$ nanocrystals can be synthesized in both fused silica and $\mathrm{Al}_{2} \mathrm{O}_{3}$ by ion implantation [7-14]. Fig. 1 is a cross-section TEM micrograph showing individual $\mathrm{Si}$ nanocrystals formed in an $\mathrm{SiO}_{2}$ film on silicon. Multiple energy implants were used to produce an excess $\mathrm{Si}$ concentration of $\sim 5 \times 10^{21} / \mathrm{cm}^{3}$ throughout the film, and the implanted sample was annealed subsequently at $1100^{\circ} \mathrm{C} / \mathrm{h}$ in

\footnotetext{
- Oak Ridge National Laboratory, managed by Lockheed Martin Energy Research Corp. for the U.S. Department of Energy under contract number DE-AC05-960R22464. Research at Fisk University is sponsored by DOE (DE-FG05-94ER45521) and at Vanderbilt University by Army Research Office (DAAHO4-93-G-0123).
} 
$\mathrm{Ar}+4 \% \mathrm{H}_{2}$. Under these conditions, the average nanocrystal diameter is $\sim 4 \mathrm{~nm}$, and there are very few nanocrystals larger than $8 \mathrm{~nm}$ in diameter. Si nanocrystals of this size encapsulated in $\mathrm{SiO}_{2}$ give rise to strong $\mathrm{PL}$ in the wavelength range of $7500 \AA$.

Fig. 2 compares PL from Si (400 keV, $\left.6 \times 10^{17} / \mathrm{cm}^{2}\right)$ implanted $\mathrm{SiO}_{2}$ following annealing with that observed from porous $\mathrm{Si}$. The PL intensity from the sample containing the $\mathrm{Si}$ nanocrystals is comparable in intensity to that from porous $\mathrm{Si}$ but shifted in wavelength as shown. The intensity of radiation from $\mathrm{Si}$ implanted $\mathrm{SiO}_{2}$ is observed also to be much more stable than that from porous Si. In the case of porous $\mathrm{Si}$, the PL intensity decreases significantly as a function of time each time a new part of the sample is exposed to the excitation beam. By contrast, the PL intensity

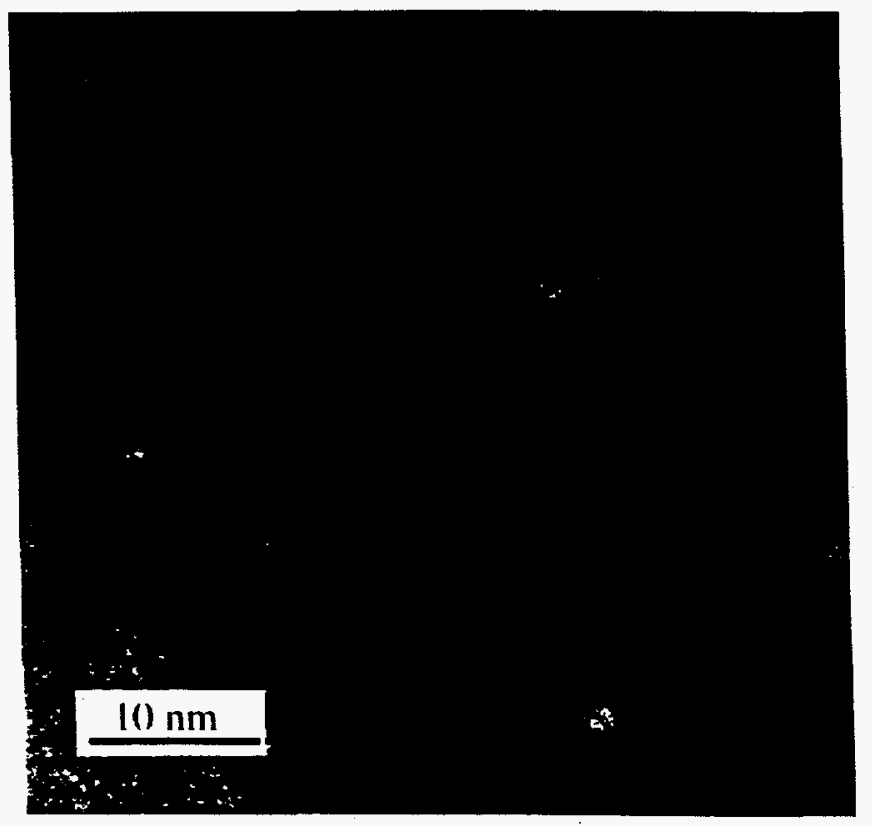

Fig. 1. Z contrast cross-section TEM micrograph showing Si nanocrystals in $\mathrm{SiO}_{2}$.

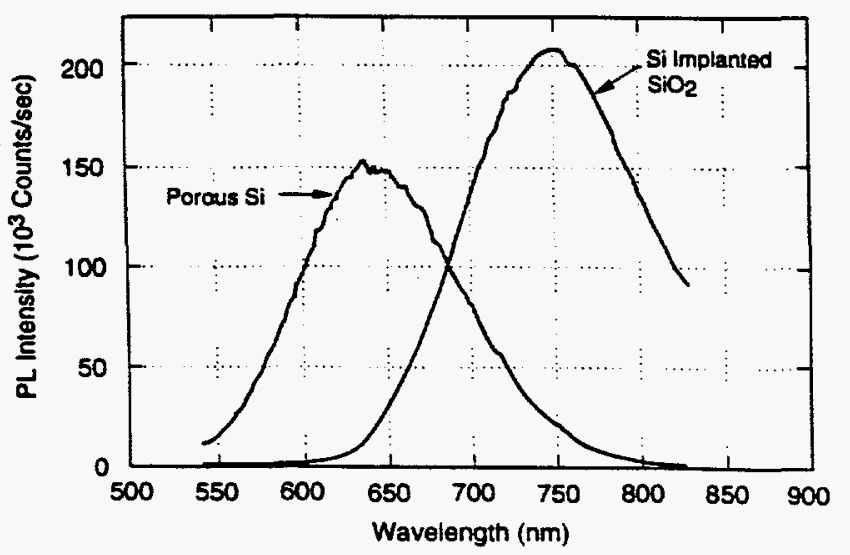

Fig. 2. $\mathrm{PL}$ arising from porous $\mathrm{Si}$ and from $\mathrm{Si}$ implanted $\mathrm{SiO}_{2}$ after annealing. The excitation wavelength was $514.5 \mathrm{~nm}$. from $\mathrm{Si}$ implanted $\mathrm{SiO}_{2}$ is not affected by similar changes in sample position.

Strong PL in the wavelength range of $7500 \AA$ is observed only after annealing the implanted sample, and the wavelength can be shifted slightly to higher energies by reducing the dose or by reducing the annealing time, both of which are expected to reduce the particle size. Fig. 3 shows the dependence on dose and demonstrates that the peak wavelength can be shifted from $-7600 \AA$ to $-6900 \AA$ by reducing the dose from $6 \times 10^{17} / \mathrm{cm}^{2}$ to $3 \times 10^{16} / \mathrm{cm}^{2}$ (at $400 \mathrm{keV}$ energy). Strong optical absorption is also observed in $\mathrm{Si}$ implanted $\mathrm{SiO}_{2}$ after annealing, and the dependence of absorption on dose is much stronger than the PL dose dependence. Fig. 4 shows the measured transmission as a function of wavelength. The absorption edge shifts to higher energy as the dose (and therefore the particle size) decreases. Results in Fig. 3 and 4 are in qualitative agreement with the behavior expected if the radiation arises from quantum confined excitions, but interface states at the nanocrystal/oxide interface cannot be ruled out as the states responsible for the emission. Optical absorption and PL emission occur at significantly different energies, so the radiation cannot be band edge emission.

\section{FORMATION OF COMPOUND SEMICONDUCTOR NANOCRYSTALS}

The synthesis of compounds by sequential implantation represents a new direction of research for high-dose ion beam synthesis. In most of the previous work on compound formation by ion implantation, the matrix material was one of the major components of the compound [23]. However, it has been demonstrated that compounds can be formed by implanting both constituents at energies chosen to give an

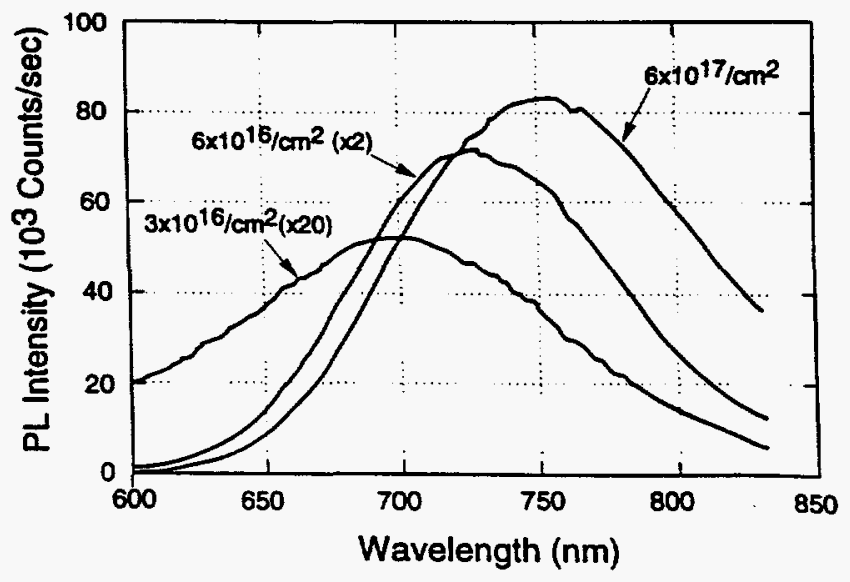

Fig. 3. $\mathrm{PL}$ arising from $\mathrm{Si}(400 \mathrm{keV})$ implanted $\mathrm{SiO}_{2}$ after annealing at $1100^{\circ} \mathrm{C} / 1 \mathrm{~h} / \mathrm{Ar}+4 \% \mathrm{H}_{2}$. 


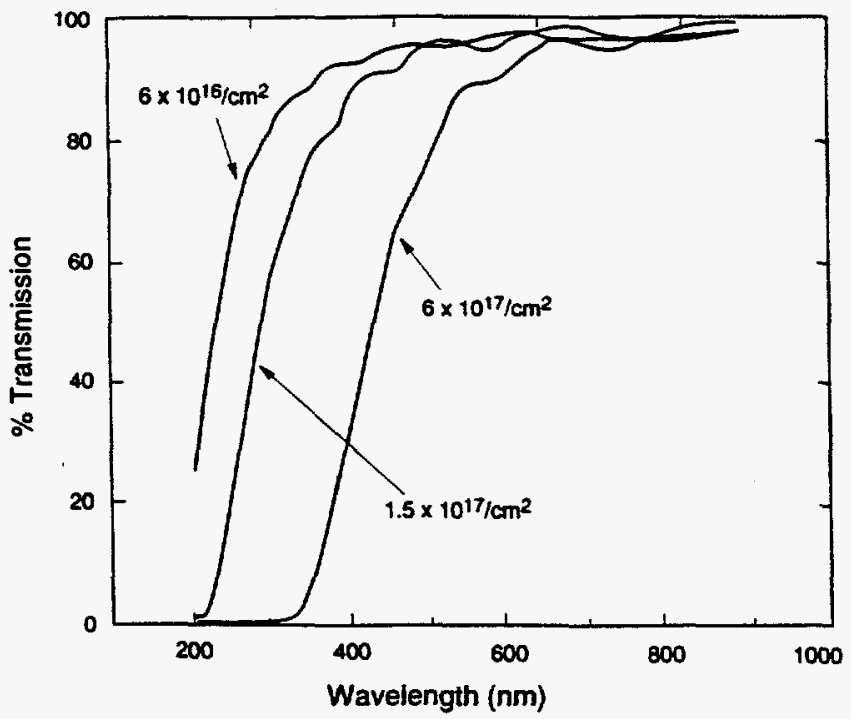

Fig. 4. Optical transmission measured through fused silica samples implanted by $\mathrm{Si}(400 \mathrm{keV})$ and annealed at $1100^{\circ} \mathrm{C} / \mathrm{h} / \mathrm{Ar}+\mathrm{H}_{2}$. Results from the implanted samples were compared with those from unimplanted fused silica.

overlap of the profiles [15-22]. Fig. 5 demonstrates that GaAs nanocrystals can be formed in $\mathrm{SiO}_{2}$, by the implantation of equal doses $\left(1.5 \times 10^{17} / \mathrm{cm}^{2}\right)$ of $\mathrm{Ga}$ (at $470 \mathrm{keV}$ ) and $\mathrm{As}$ (at $500 \mathrm{keV}$ ) followed by annealing $\left(1000^{\circ} \mathrm{C} / 1 \mathrm{~h} / \mathrm{Ar}+\mathrm{H}_{2}\right)$. The strong diffraction peaks arising from $\mathrm{GaAs}$ are observed in addition to scattering from the amorphous substrate $\left(\mathrm{SiO}_{2}\right)$ and the $\mathrm{Si}(200)$ multiple scattering peak from the underlying substrate. The sizes of nanoparticles in Fig. 5 extend to several hundred angstroms in diameter, but the nanoparticle size depends strongly on the dose, the annealing conditions, and the order of the implant [24].

Group II-VI compound semiconductor nanocrystals can also be formed by the sequential implantation of various combinations of Group II and Group VI ions [19]. The X-ray diffraction results in Fig. 6 show that CdSe nanocrystals are formed by the implantation of $\mathrm{Cd}$ and $\mathrm{Se}$, and that $\mathrm{CdS}$ nanocrystals result from the implantation of overlapping profiles of overlapping profiles of $\mathrm{Cd}$ and $\mathrm{S}$. For the case of $\mathrm{Cd}+0.5 \mathrm{Se}+0.5 \mathrm{~S}$, the diffraction peaks are intermediate between those of CdSe and CdS, suggesting that the mixed chalcogenide $\mathrm{Cd}_{1} \mathrm{Se}_{0.5} \mathrm{~S}_{0.5}$ has been formed by the implantation of three ions. Results from Fig. 6 are supported by Raman measurements on the same samples.

A wide range of nanocrystals can be formed also in singlecrystal silicon by sequential implantation of the individual constituents $[15-17,21,22]$. One example is the formation of GaAs encapsulated in crystalline silicon [21]. Fig. 7 is a $\theta-2 \theta$ scan along the [001] diameter of silicon showing strong peaks arising from the encapsulated GaAs in addition to the expected $\mathrm{Si}$ (004) reflection. In this case, implantation at elevated temperatures was used to preserve the crystallinity of the matrix during implantation, and elevated temperature annealing was used to reduce residual damage and promote nanocrystal growth. Detailed studies show that the GaAs nanocrystals formed in $\mathrm{Si}$ are three dimensionally oriented with respect to the matrix.

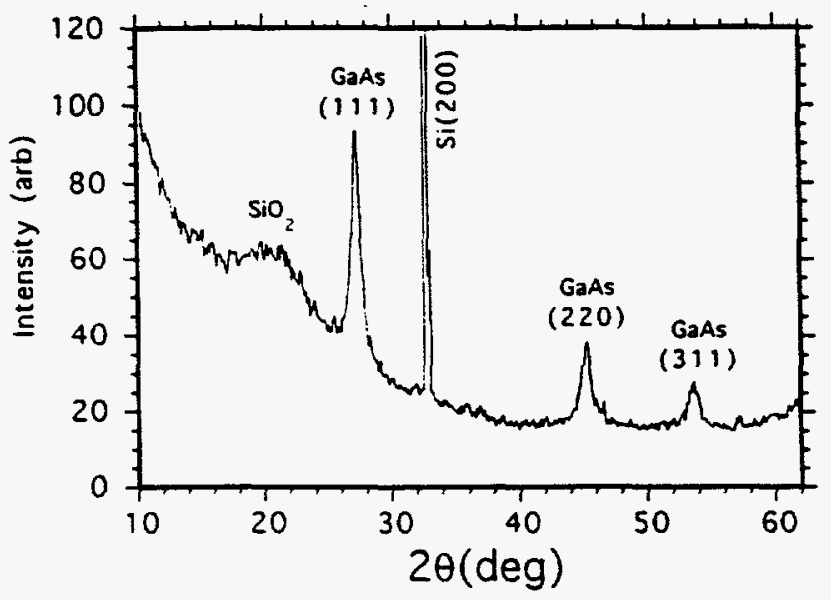

Fig. 5. X-ray diffraction demonstrating the formation of GaAs nanocrystals in $\mathrm{SiO}_{2}$ by the implantation of $\mathrm{Ga}$ and $\mathrm{As}$.

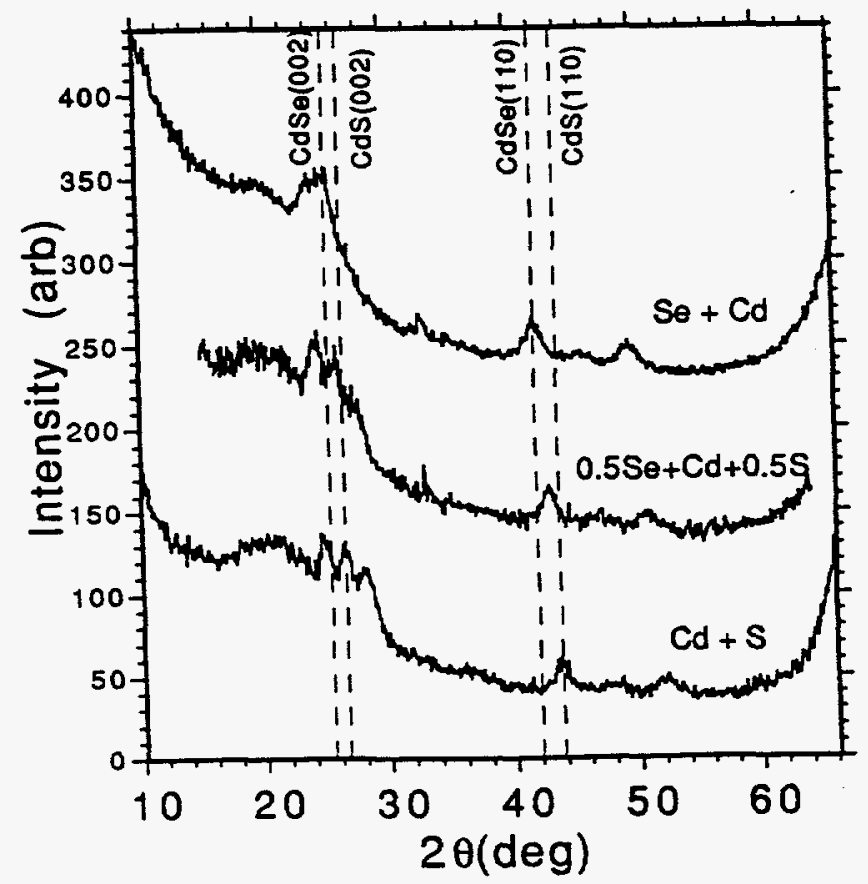

Fig. 6. Compound semiconductor nanocrystals formed by the implantation of equal doses $\left(1 \times 10^{17} / \mathrm{cm}^{2}\right)$ of Group $\mathrm{II}$ and Group $\mathrm{VI}$ ions into $\mathrm{SiO}_{2}$, followed by annealing $\left(1000^{\circ} \mathrm{C} / 1 \mathrm{~h} / \mathrm{Ar}+\mathrm{H}_{2}\right)$. 


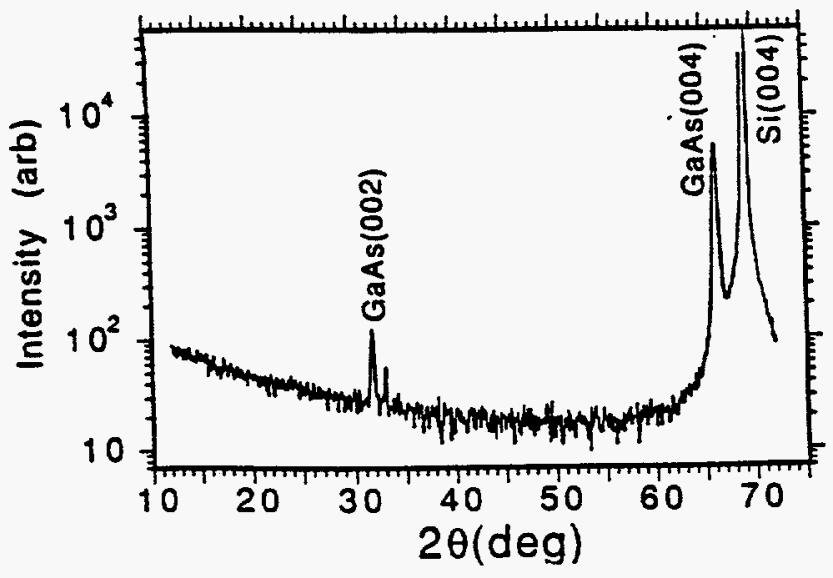

Fig. 7. X-ray diffraction results showing GaAs nanocrystals formed by the implantation of equal doses $\left(1 \times 10^{17} / \mathrm{cm}^{2}\right)$ of $\mathrm{Ga}$ and $\mathrm{As}$ into crystalline silicon, followed by annealing $\left(1000^{\circ} \mathrm{C} / 1 \mathrm{~h} / \mathrm{Ar}+\mathrm{H}_{2}\right)$.

The synthesis of compounds by sequential ion implantation is a new direction of research for high-dose ion implantation because it presents opportunities to form many more compounds than previously demonstrated. These compounds can be synthesized in a variety of matrices. Table I shows a list of the compound semiconductor nanocrystals we have synthesized in $\mathrm{SiO}_{2}, \mathrm{Al}_{2} \mathrm{O}_{3}$, and crystalline $\mathrm{Si}$ [18-21], and results of others are reported in [15-17,22]. Nanocrystal size and size distribution depend on the dose, the annealing conditions, and the order of the implant. In amorphous $\mathrm{SiO}_{2}$, the nanocrystals are randomly oriented, but in crystalline matrices, the nanocrystals are three dimensionally oriented with respect to the matrix. Ion implantation may be the most convenient method to produce most of these nanocrystals, and the method can be used to encapsulate them in a wide range of host matrices.

TABLE I

NANOCRYSTAL COMPOUNDS FORMED BY SEQUENTIAL IMPLANTATION. AN $x$ INDICATES THAT THE COMPOUND WAS FORMED IN THE GIVEN MATRIX.

\begin{tabular}{|l|c|c|c|}
\hline \multirow{2}{*}{ Nanocrystal } & \multicolumn{3}{|c|}{ Substrate } \\
\cline { 2 - 4 } & $\mathrm{SiO}_{2}$ & $\mathrm{Al}_{2} \mathrm{O}_{3}$ & $\mathrm{Si}$ \\
\hline SiGe & $\mathrm{x}$ & $\mathrm{x}$ & $\mathrm{x}$ \\
\hline $\mathrm{GaAS}$ & $\mathrm{x}$ & $\mathrm{x}$ & $\mathrm{x}$ \\
\hline $\mathrm{InAs}$ & $\mathrm{x}$ & & $\mathrm{x}$ \\
\hline $\mathrm{GaP}$ & $\mathrm{x}$ & & $\mathrm{x}$ \\
\hline $\mathrm{InP}$ & $\mathrm{x}$ & $\mathrm{x}$ & \\
\hline $\mathrm{CdS}$ & $\mathrm{x}$ & & \\
\hline $\mathrm{CdSe}$ & $\mathrm{x}$ & $\mathrm{x}$ & \\
\hline $\mathrm{CdSe} 0.5 \mathrm{~S}_{0.5}$ & & & \\
\hline $\mathrm{GaN}$ & & & \\
\hline
\end{tabular}

\section{REFERENCES}

[1] See for example A. P. Alivisatos, "Semiconductor clusters, nanocrystais. and quantum dots," Science 271, 933 (1996).

[2] G. W. Arnold. "Near-surface nucleation and crystailization of an ion implanted lithia-alumina-silica glass." J. Appl. Phys. 46, 4466 (1975).
[3] K. Fukuami, A. Chayahara, M. Satou, J. Hayakawa, M Hangyo, S. Nakashima, "Au+-ion implanted silica glass with nonlinear optical property," Jap. J. Appl. Phys. 30, L742 (1991).

[4] R. H. Magruder, L. Yang, R. F. Haglund, C. W. White, C. Yang R. Dorsinville, and R. R. Alfando, "Optical properties of gold nanocluster composites formed by deep ion implantation in silica," Appl. Phys. Lett. 62, 1730 (1993).

[5] C. W. White, D. S. Zhou, J. D. Budai, R. A. Zuhr, R. H. Magruder. and D. H. Osborne, "Colloidal Au nanoclusters formed in fused silica by MeV ion implantation and annealing," Mat. Res. Soc. Symp. Proc. 316, 499 (1994).

[6] R. H. Magruder, R. F. Haglund, L. Yang, J. E. Wittig, and R. A. Zuhr, "Physical and optical properties of $\mathrm{Cu}$ nanoclusters fabricated by ion implantation in fused silica," J. Appl. Phys. 76, 708 (1994).

[7] H. Atwater, K. V. Shcheglov, S. S. Wong, K. J. Vahala, R. C. Flagan. M. L. Brongersma, and A. Polman, "Ion beam synthesis of luminescent $\mathrm{Si}$ and Ge nanocrystals in a silicon dioxide matrix," Mat. Res. Soc. Symp. Proc. 316, 409 (1994).

[8] H. Takagi, H. Ogawa, Y. Yamazaki, A. Ishizaki, and T. Nakagiri, "Quantum size effects on photoluminescence in ultrafine $\mathrm{Si}$ particles." Appl. Phys. Lett. 56, 2379 (1990).

[9] Y. Maeda, N. Tsukamoto, Y. Yazawa, Y. Kanemitsu, and Y. Masumoto, "Visible photoluminescence of Ge microcrystals embedded in $\mathrm{SiO}_{2}$ glassy matrices," Appl. Phys. Lett. 59, 3168 (1991).

[10] T. Shimizu-Iwayama, K. Fujita, S. Nakao, K. Saitoh, T. Fujita, and $\mathrm{N}$. Itoh, "Visible photoluminescence in $\mathrm{Si}^{+}$implanted silica glass," $J$. Appl. Phys. 75, 7779 (1994).

[11] J. G. Zhu, C. W. White, J. D. Budai, S. P. Withrow, and Y. Chen "Semiconductor nanocrystals formed in $\mathrm{SiO}_{2}$ by ion implantation," Mat. Res. Soc. Symp. Proc. 358, 175 (1995)

[12] J. G. Zhu, C. W. White, J. D. Budai, S. P. Withrow, and Y. Chen, "Growth of $\mathrm{Ge}, \mathrm{Si}$, and $\mathrm{SiGe}$ nanocrystais in $\mathrm{SiO}_{2}$ matrices," J. Appl. Phys. 77, 4386 (1995).

[13] K. S. Min, K. Y. Shcheglov, C. M. Yang, H. A. Atwater M. L. Brongersma, and A. Polman, "The role of quantum-confined excitons vs defects in the visible luminescence of $\mathrm{SiO}_{2}$ films containing Ge nanocrystals," Appl. Phys. Lett. 68, 2511 (1996).

[14] C. W. White, J. D. Budai, S. P. Withrow, S. J. Pennycook. D. M. Hembree, Jr., D. S. Zhou, T. Yo-Dihn, and R. H. Magruder, "Oriented $\mathrm{Si}$ and $\mathrm{Ge}$ nanocrystals formed in $\mathrm{Al}_{2} \mathrm{O}_{3}$ by ion implantation and annealing," Mat. Res. Soc. Symp. Proc. 316, 487 (1994).

[15] S. Yu. Shiryaev and A. Nylandstead Larsen, "High-dose mixed $\mathrm{Ga} / \mathrm{As}$ and $\mathrm{Ga} / \mathrm{P}$ ion implantations in silicon single crystals," Nucl. Inst. and Meth in Phys. Res. B 80/81, 846 (1993)

[16] S. Yu. Shiryaev, A. Nylandsted Larsen, and M. Deicher, "The chemical interaction between high-concentration, mixed-ionimplanted group-III and -V impurities in silicon," J. Appl. Phys. $\mathbf{7 2}$ 410 (1992).

[17] P. Madakson, E. Ganin, and J. Karasinski, “ $\mathrm{As}^{+}$and $\mathrm{Ga}^{+}$implantation and the formation of buried GaAs layers in silicon," J. Appl. Phys. 67. $4053(1990)$

[18] C W. White, J. D. Budai, J. G. Zhu, S. P. Withrow, R. A. Zuhr, Y. Chen, D. M. Hembree, R. H. Magruder, and D. O. Henderson, "Compound semiconductor nanocrystals formed by sequential ion implantation," Mat. Res. Soc. Symp. Proc. 358, 169 (1995).

[19] C. W White, J. D. Budai, J. G. Zhu S. P. Withrow, D. M. Hembree D. O. Henderson, A. Ueda, Y.S. Tung, and R. Mu, "Nanocrystals and quantum dots formed by high-dose ion implantation," Mat. Res. Soc. Symp. Proc. 396, 377 (1996).

[20] C. W White, J. D. Budai, J. G. Zhu S. P Withrow, R A Zuhr D. M. Hembree, D. O. Henderson, A. Ueda, Y. S. Tung, R. Mu, and R. H. Magruder, "GaAs nanocrystals formed by sequential ion implantation," J. Appl. Phys. 79, 1876 (1996).

[21] C W White, J. D. Budai J. G. Zhu, S. P. Withrow, and M. J. Aziz "Ion-beam synthesis and stability of GaAs nanocrystals in silicon," Appl. Phys. Lett. 68, 2389 (1996).

[22] A. K. Rai, R. S. Bhattacharya, and S. C. Kung, "Formation of TiN phase in $\mathrm{SiO}_{2}$ and $\mathrm{Si}$ through ion implantation of constituent elements," Materials Letters 13, 35 (1992).

[23] See for example A. E. White, K. T. Short, R. C. Dynes, J. P. Garno, and J. M. Gibson, "Mesotaxy: single-crystal growth of buried $\mathrm{CoSi}_{2}$ layers," Appl. Phys. Lett. 50. 95 (1987).

[24] J. G. Zhu, C. W. White, D. J. Wallis, J. D. Budai, S. P. Withrow, and D. O. Henderson, "Synthesis and properties of GaAs nanocrystals in $\mathrm{SiO}_{2}$ formed by ion implantation," Mat. Res. Soc. Symp. Proc. 396, $447^{-}(1996)$ 